This item was submitted to Loughborough's Research Repository by the author.

Items in Figshare are protected by copyright, with all rights reserved, unless otherwise indicated.

\title{
MIMO (Multiple-Input-Multiple-Output) control for optimising the future gasoline powertrain - A survey
}

PLEASE CITE THE PUBLISHED VERSION

https://doi.org/10.4271/2017-01-0600

\section{PUBLISHER}

(C) SAE International

\section{VERSION}

AM (Accepted Manuscript)

\section{PUBLISHER STATEMENT}

This work is made available according to the conditions of the Creative Commons Attribution-NonCommercialNoDerivatives 4.0 International (CC BY-NC-ND 4.0) licence. Full details of this licence are available at: https://creativecommons.org/licenses/by-nc-nd/4.0/

\section{LICENCE}

CC BY-NC-ND 4.0

\section{REPOSITORY RECORD}

Petrovich, Simon, Kambiz Morteza Ebrahimi, and Antonios Pezouvanis. 2018. "MIMO (multiple-input-multipleoutput) Control for Optimising the Future Gasoline Powertrain - A Survey". figshare. https://hdl.handle.net/2134/33366. 


\title{
MIMO Control for Optimising the Future Gasoline Powertrain - A Survey
}

Authors: Petrovic, Simon, Ebrahimi, Kambiz, Pezouvanis, Antonios

Affiliation: Loughborough University, United Kingdom

\begin{abstract}
This paper surveys publications on automotive powertrain control, relating to modern GTDI (Gasoline Turbocharged Direct Injection) engines.

The requirements for gasoline engines are optimising the airpath but future legislation mandates not only a finely controlled airpath but also some level of electrification.

Fundamentals of controls modelling are revisited and advancements are highlighted. In particular, a modern GTDI airpath is presented based on basic building blocks (volumes, turbocharger, throttle, valves and variable cam timing or VCT) with an example of a system interaction, based on boost pressure and lambda control. Further, an advanced airpath could be considered with applications to downsizing and fuel economy.
\end{abstract}

A further electrification step is reviewed which involves interactions with the airpath and mandates a robust energy management strategy. Examples are taken of energy recovery and e-machine placement.

Control-oriented models of gasoline engines are reviewed, and challenging control problems for conventional engines and hybrid vehicle powertrains are discussed, in particular relating to consideration of the complex interactions.

A systems approach is needed to understand the attribute trade-off, with fuel consumption, emissions, as well as energy storage on a particular drive cycle. This mandates an optimisation methodology and appropriate problem formulation of objective, states and constraints. A discussion of optimisation techniques is considered.

Finally, a comprehensive list of references is provided.

Key Words: Automotive, powertrain, MIMO (Multi-Input, Multi-Output), modelling, control, electrification, energy recovery, optimisation. 


\section{References (A Start)}

AUTOMOTIVE POWERTRAIN CONTROL - A SURVEY Jeffrey A. Cook, Jing Sun, Julia H. Buckland, llya V. Kolmanovsky, Huei Peng, and Jessy W. Grizzle , Asian Journal of Control, Vol. 8, No. 3, pp. 237-260, September 2006

Modeling and Control of Automotive Powertrain Systems: A Tutorial, Jing Sun, llya Kolmanovsky, Jeffrey A. Cook, and Julia H. Buckland, 2005 American Control Conference June 8-10, 2005. Portland, OR, USA

Simulation of the engine and automobile driveability during a driving cycle, Matej Juraj,

Elektrotechnika 06.02.2013

Modeling and Control of Turbocharged SI and DI Engines, L. Eriksson, Vehicular Systems, Dept. of Electrical Engineering, Linköping University, SE-58183 Linköping - Sweden, Oil \& Gas Science and Technology - Rev. IFP, Vol. 62 (2007), No. 4, pp. 523-538.

Control Oriented Modeling of Turbocharged (TC) Spark Ignition (SI) Engine, R. Sharma, D. Nesic and C. Manzie, The University of Melbourne, SAE 2009-01-0684

MODELING AND SOLVING AN ENGINE INTAKE MANIFOLD WITH TURBO CHARGER FOR PREDICTIVE CONTROL, Long Xie, Harutoshi Ogai, and Yasuaki Inoue, Asian Journal of Control, Vol. 8, No. 3, pp. 210-218, September 2006

A Coordinated Approach for Throttle and Wastegate Control in Turbocharged Spark Ignition Engines, Patrick Gorzelic, Erik Hellström, Anna Stefanopoulou, Li Jiang, and Srinath Gopinath

A Mean-Value Model for Control of Homogeneous Charge Compression Ignition „HCCI...Engines, D. J. Rausen, A. G. Stefanopoulou, Journal of Dynamic Systems, Measurement, and Control SEPTEMBER 2005, Vol. 127 / 355 7.Multivariable Feedback Control: Analysis and Design, Skogestad, Sigurd, Postlethwaite lan, Wiley, 4 Nov 2005, pp. 82-91.

Nonlinear Control in Automotive Engine Applications, Mrdjan Jankovic

Catalyst Aging Method for Future Emissions Standard Requirements, Dmitry Ignatov, Carsten Küpper, Stefan Pischinger Institute for Combustion Engines, RWTH-Aachen University Michael Bahn, Winston Betton, Oliver Rütten, Rolf Weinowski FEV Motorentechnik, 2010-01-1272 


\section{Introduction}

\subsection{Organisation of Paper}

1.2

II. Fundamental GTDI Subsystems

The basic model consists of a GTDI engine with the following parts: throttle body, intake manifold, torque generation and engine rotational dynamics. Subsystems are

turbocharger, EGR, variable valve timing, pressure and temperature dynamics, as well as an emissions model.

\subsection{Fundamental GTI Airpath}

\subsection{Control of VCT}

Common systems are VCT, CAM phasing, most generic is twin-independent:

\subsection{Aftertreatment}

Need to take into account NOx conversion efficiency

GPF and LNT for lean burn applications

\subsection{Control of GTDI Engine}

Schematic is boost control (or TIP) using VNT or WG and lambda control pedal ->Tq->boost demand + air demand (sensor set)

III. Advanced GTDI Airpath Control

Further additions for the airpath include EGR, cyl deact

\subsection{Advanced Airpath Control}

HP, LP EGR as fuel consumption technology and an enabler for knock mitigation/downsizing. Cylinder deactivation?

\subsection{Energy Recovery}

Basic PT not so efficient - look at overall fuel power/power at wheels

TG and TEG

Opportunities: reduced Texh, no enrichment cost saving on turbine material, use VNT instead of WG

Improve efficiency more, leaner, improved cost on cat (less Pt, Pd)

$\mathrm{CO} 2$ reduction $\mathrm{w} /$ better regen harnessing via energy recovery

\section{Modelling Philosophy}

As outlined in transfer report.

v. System Interaction: An Example

Why MIMO? Decoupling?

Throttle inlet pressure controlled by wastegate, AFR controlled by fuelling REF decoupling

VI. Gasoline Hybridisation

Complex systems, e.g. powersplit, but in addition crank ISG, belt ISG, or Px with electric drive capability

VII. System Optimisation and Integration

The standard drive cycle was NEDC, average xyz. However, for EUROVII (2017), WLTC will be the homologation drive cycle (ref) with different levels of real-world driving being introduced in 2021 (ref). This represents challenges not only for technology 
development, but also for calibration and system optimisation.

6.1 Drive cycle impact (WLTC, RDE)

Cycle and opportunities for regen

6.2 Optimisation Techniques:

Dynamic and Linear Programming, Pontryagin's Maximum Principle, ECCS, MPC, Others:

Direct Multiple Shooting

Trade-off fuel, NOx, PN, Pareto front

PSR (Powersplit Ratio) in FH

VIII. Conclusions 


\section{Fundamental GTDI Subsystems}

The basic model consists of a GTDI engine with the following parts: throttle body, intake manifold, torque generation and engine rotational dynamics. Subsystems are turbocharger, EGR, variable valve timing, pressure and temperature dynamics, as well as an emissions model.

\section{Fundamental GTI Airpath}

Intake manifold dynamics can be represented using conservation of energy as follows:

$$
\dot{p}_{\iota}=\frac{\gamma R}{V_{i}}\left(T_{i c} W_{c i}+T_{r} W_{x i}-T_{i} W_{i e}\right)
$$

with $\mathrm{W}_{\mathrm{ci}}, \mathrm{W}_{\mathrm{xi}}, \mathrm{W}_{\mathrm{ie}}$ mass flow rates through the compressor, exhaust to intake manifold and throttle. The differential equation for the mass stored in the manifold, $m_{i}$, follows from amass balance:

$$
\dot{m}_{\imath}=W_{c i}+W_{x i}-W_{i e}
$$

The Ideal Gas Law is used to calculate the intake manifold temperature, $T_{i}$ :

$$
T_{i}=\frac{V_{i}}{R m_{i}} p_{i}
$$

Since external EGR may be included, and indeed, the engine may run lean $(\lambda>0)$, burned gas fraction needs to be considered, although internal EGR is not (REF):

$$
\dot{F}_{l}=\frac{W_{c i}\left(F_{a}-F_{i}\right)+W_{x i}\left(F_{x}-F_{i}\right)}{m_{i}}
$$

with the ambient burned-gas fraction, $F_{a}$, zero.

A similar analysis follows for the exhaust manifold.

EGR valve and throttle flows and wastegate are flow restrictions, represented by a standard orifice equation:

$$
W_{x i}=\frac{A_{r}\left(x_{r}\right) p_{x}}{\sqrt{R T_{x}}} \Phi\left(\frac{p_{i}}{p_{x}}\right), W_{i e}=\frac{A_{r}\left(x_{r}\right) p_{x}}{\sqrt{R T_{x}}} \Phi\left(\frac{p_{i}}{p_{a}}\right)
$$

Where $A_{r}, A_{r}$ represent the respective effective valve flow areas, as a function of position, Ta, Tx are the temperatures. The function $\Phi$ represents the effects of pressure ratio on the valve flow (REF):

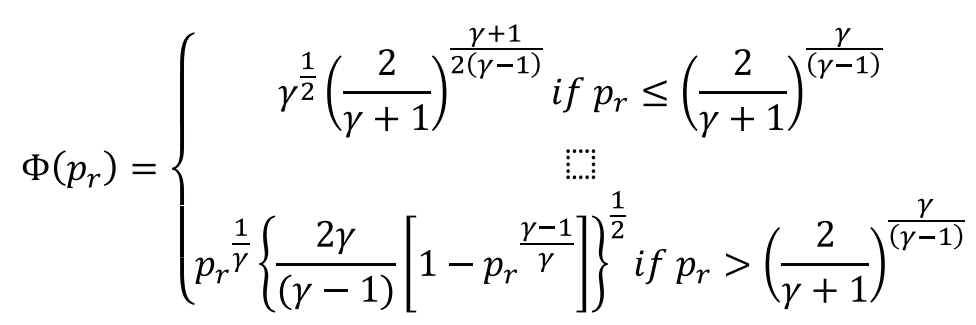

with $\gamma$ the ratio of specific heats.

Another flow restriction is a cooler element (EGR cooler) and here the intercooler:

$$
W_{c i}=\left\{\begin{array}{c}
\sqrt{\frac{P_{2}\left(P_{2}-P_{i c}\right)}{C_{f r} T_{2}}} \text { if }\left(P_{2}-P_{i c}\right)>P_{l i n} \\
\sqrt{\frac{P_{2}}{C_{f r} T_{2}}} \frac{\left(P_{2}-P_{i c}\right)}{\sqrt{P_{l i n}}} \text { otherwise }
\end{array}\right.
$$

Where $P 2, T 2$ are the upstream cooler pressure and temperature, $C f r$ is a quadratic pressure drop constant and Plin represents a threshold for laminar flow. 
And Temp drop

The dynamics of the engine shaft is described by

$$
\dot{N}=\frac{60}{2 \pi} \frac{T_{b}-T_{l}}{J_{e}+J_{d r}}
$$

where $\mathrm{T}_{\mathrm{b}}=\mathrm{T}_{\text {ind }}+\mathrm{T}_{\mathrm{fr}}$ is the brake torque, i.e., the difference between the torque produced by the combustion event (indicated torque) and all friction torques (negative) in the engine and its auxiliaries; $\mathrm{Tl}$ is the load torque. In the denominator, Je and Jdr are the engine and the driveline inertias, respectively. Torques can be further estimated by regression models based on power and/or fuelling (REF).

\section{Control of VCT}

Common systems are VCT, CAM phasing, most generic is twin-independent:

VCT (ref Ford) offers opportunities to improve the engine performance and emissions, by either hydraulically or electrically phasing the CAMs: the most generic is TI-VCT, where both CAMs can be phased independently. By retarding the exhaust CAM phasing, more exhaust residuals can be trapped in the cylinder post combustion, thereby reducing NOx emissions. This phenomenon is called "internal EGR." (ref)

Indeed, for optimised mapping, reduced locus of points (ref Ford).

For the engine equipped with VCT, the mass air flow rate into the cylinders Wcyl is represented as a function of engine speed $\mathrm{N}$, intake manifold pressure Pman, intake valve opening IVO and cam phasing, $\xi_{\mathrm{CAM}}$ as follows:

PLOT

$$
W_{c y l}=f\left(N, P_{\text {man }}, I V O, \xi_{\text {CAM }}\right)
$$

Uncompensated, however, VCT acts as a disturbance to the breathing process, compromising driveability and substantially reducing its effectiveness in reducing emissions. REF Ford

\section{Emissions and Aftertreatment}

$\mathrm{HC}, \mathrm{CO}, \mathrm{PN}, \mathrm{NOx}$ need to take into account. Urs C

Need to take into account NOx conversion efficiency

GPF and LNT for lean burn applications

BSNOx plots

\section{Control of GTDI Engine}

Schematic is boost control (or TIP) using VNT or WG and lambda control

pedal $->$ Tq->boost demand + air demand (sensor set)

\section{Advanced GTDI Airpath Control}

Further additions for the airpath include EGR, cyl deact

\section{Advanced Airpath Control}

HP, LP EGR as fuel consumption technology and an enabler for knock mitigation/downsizing. Cylinder deactivation?

\section{Energy Recovery}

Basic PT not so efficient - look at overall fuel power/power at wheels

TG and TEG

Opportunities: reduced Texh, no enrichment cost saving on turbine material, use VNT instead of WG

Improve efficiency more, leaner, improved cost on cat (less Pt, Pd)

$\mathrm{CO} 2$ reduction $\mathrm{w} /$ better regen harnessing via energy recovery

\section{Modelling Philosophy}

As outlined in transfer report.

\section{System Interaction: An Example}

Why MIMO? Decoupling?

Standard controllers for complex GTDI systems are independent SISO, so for example, fuelling controls the exhaust lambda and the wastegate or VNT controls the boost pressure or throttle inlet pressure. However, tight control is a necessity for both emissions compliance and transient performance. A MIMO based structure can take into account couplings or interactions and improve the controller performance.

If the system is diagonally dominant, then input and outputs on the main transfer functional diagonal can be paired; this is called decentralised control (REF). In Diesel systems, decentralised control is the preferred, with the EGR valve controlling 
the EGR rate and the VNT controlling the boost pressure (REF).

However, if interactions are to be taken into account, the Relative Gain Array (REF) can be constructed, a measure which can be constructed in order to decide a suitable input/output pairing when applying a decentralized control structure over a certain frequency range. It can also be used to decide whether a certain pairing should be avoided. Since frequency is considered, it is possible to take into account the interaction by switching over a frequency range, e.g. on a tip-in (max freq) to steady state $(s=j \omega=0)$

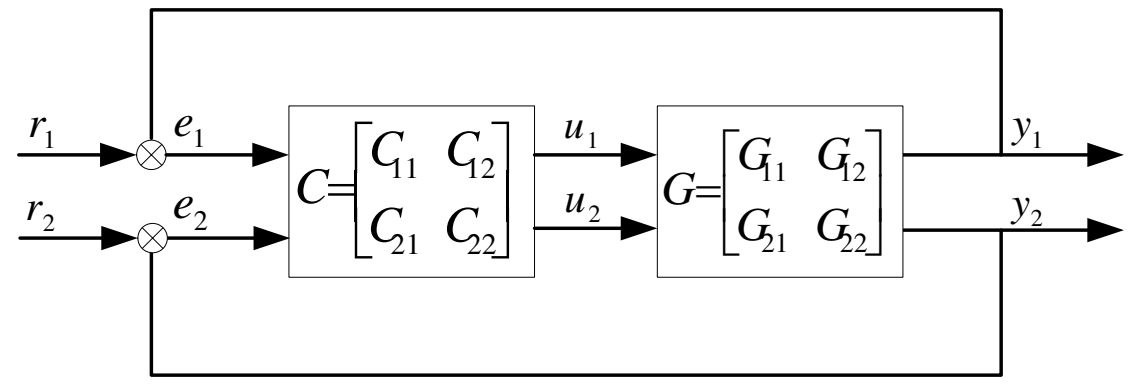

Figure 1: Block diagram of partitioned multivariable control system.

Figure 1 shows a generic multivariable control system, including interaction terms $C i j$, Gij, $i \neq j$; sensor dynamics and transport delay are omitted for simplicity, but need to be included for airpath control. Generally, when interactions are taken into account, the controller has a form:

$$
\left(\begin{array}{l}
u_{1} \\
u_{2}
\end{array}\right)=\left(\begin{array}{ll}
C_{11} G_{11}+C_{12} G_{21} & C_{11} G_{12}+C_{12} G_{22} \\
C_{21} G_{11}+C_{22} G_{21} & C_{21} G_{12}+C_{22} G_{21}
\end{array}\right)\left(\begin{array}{l}
e_{1} \\
e_{2}
\end{array}\right)
$$

For a relevant airpath example, the throttle inlet pressure (or manifold pressure) is controlled by the wastegate, AFR controlled by fuelling (lambda control).

$$
R G A(G(j \omega))=\Lambda(G(j \omega)) \triangleq G((j \omega)) \times\left(G(j \omega)^{-1}\right)^{T}
$$

with $\mathrm{x}$ denoting elementbyelement multiplication (the Schur product). Example

PLOT

Modifications (REF)

\section{Gasoline Hybridisation}

For a small gasoline engine, the amount of opportunity largely determined by BSFC topology/flatness of BSFC. Potential, for a given e-power, higher on NEDC due to higher low-load frequency. Interaction with technologies impacting this topology, e.g., LP EGR or VDE needs to be analysed. Figure 2 shows a typical trace.

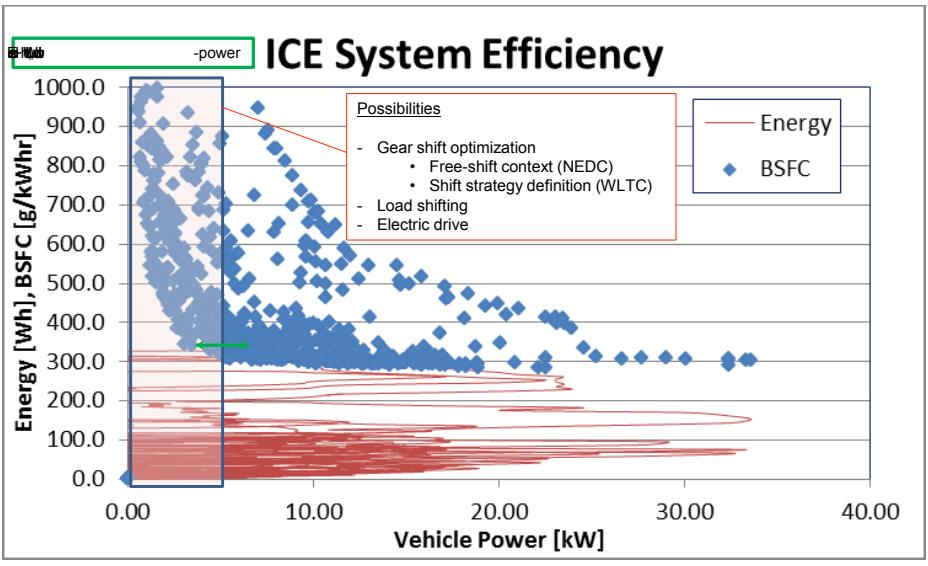

Figure 2: ICE engine efficiency over a WLTC drive cycle. 
REF classifies HEV's into 3 main categories: Stop/Start, MHEV and Strong; Stop/Start requires minimal changes to engine, starter and battery and may include some basic regenerative braking, whereas MHEV

Complex systems, e.g. powersplit, but in addition crank ISG, belt ISG, or Px with electric drive capability. $75 \mathrm{~g} / \mathrm{km} \mathrm{CO} 2$ fleet average not achievable using ICE only. Several architectures, transmission based. A convenient classification for HEV's can be Stop/Start only, MHEV, Strong (REF). This section focusses on subsets, collectively called Px.

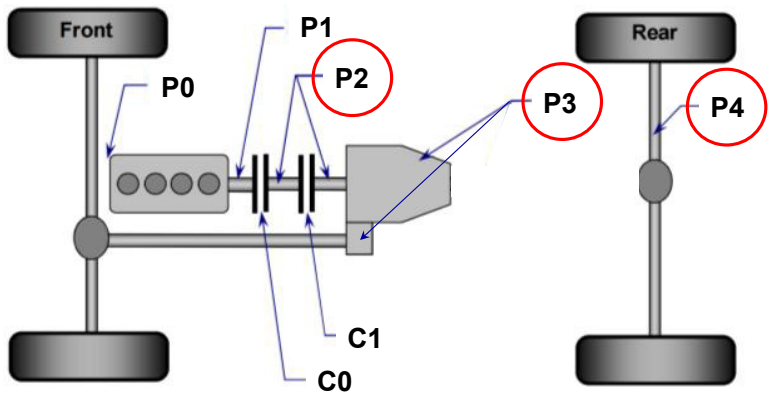

Figure 3: Powertrain electrification topologies.

Complex systems

\section{Package and tables}

\section{Reqts on powergrid}

For an attribute summary, REF. Range, level of torque assist and regenerative energy harnessing depend on the component sizing and topology. A P0/P1 architecture does not permit electric drive, but features such as sailing (for manual transmission variants) require an electronically-controlled clutch. Some technologies (REF) could perform sailing with no eclutch. A P3 (emachine on transmission output) enables electric driving, however, axle-based solutions (front or rear NSK) enable direct thru to road power to the wheels.

Beyond increased capability for energy recuperation, migration to an mHEV architecture from P2 and beyond, facilitates a number of additional autonomous-capable mode features.

The more detailed comparison of the capability of each architecture in terms of each such feature depends heavily of the details of the implementation and cannot be easily generalized

Transmission summary? The transmission integrated solution has been selected for the P2 and P3 configuration for efficiency and package reasons.

Simulation studies ...

Committee on the Assessment of Technologies for Improving Fuel Economy of Light-Duty Vehicles, "Cost, Effectiveness and Deployment of Fuel Economy Technologies for Light-Duty Vehicles," THE NATIONAL ACADEMIES PRESS, ISBN 978-0-309-37388-3, 2015 


\section{System Optimisation and Integration}

The standard drive cycle was NEDC, average xyz. However, for EUROVI (2017), WLTC will be the homologation drive cycle (ref) with different levels of real-world driving being introduced in 2021 (ref). RDE will include a CF (Conformity Factor, relative emissions in real-world driving compared to a reference WLTC), with intermediate introduction Sep 2017, final by Jan 2021, with additional ambient T, P, gradient and other noise factors. This represents challenges not only for technology development, but also for the aftertreatment performance, calibration and system optimisation.

\begin{tabular}{|l|c|c|}
\hline & NEDC & $\begin{array}{c}\text { WLTP } \\
\text { Class 3 }\end{array}$ \\
\hline V max / kph & 120 & 135 \\
\hline Time/s & 1180 & 1800 \\
\hline Length / km & 11 & 23 \\
\hline V av / kph & 34 & 46 \\
\hline Idle & 220 s (22\%) & $2425(13.8 \%)$ \\
\hline
\end{tabular}

Figure 4:Comparison of drive cycle characteristics.

In the US, 2017-2025 will see Tier 3 (EPA) and LEVIII (CARB).

\subsection{Drive cycle impact (WLTC, RDE)}

Using the WLTP cycle for a sub 2 tonne MPV (Multi-Purpose Van), opportunities for energy recovery were analysed by breaking down the decelerations (coasting and braking) and calculating the total braking energy. The process is shown in Figure 5 for Phase 1 Class 3 vehicle. Of course, not all this can be recovered, due to heat loss.

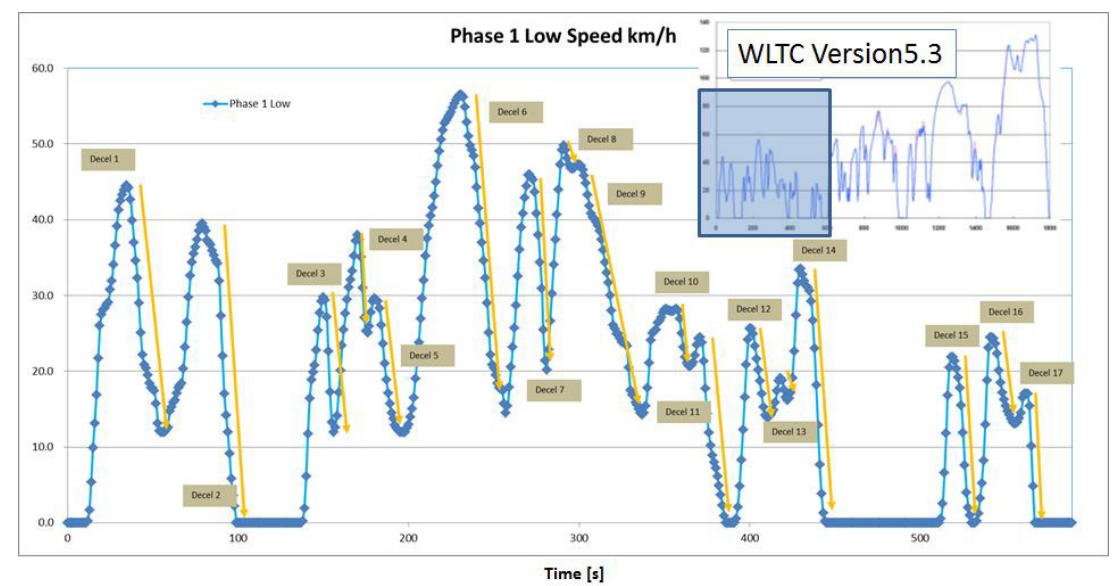

Figure 5: WLTC drive cycle (Phase I Low) potential.

As a reference, with $100 \%$ efficiency, the NEDC offers $1.03 \mathrm{MJ}$ (871W average over the whole cycle), but the WLTP offers $2.9 \mathrm{MJ}(1645 \mathrm{~W}$ on average).Assuming a efficiency factor for braking, this analysis helps perform electric machine matching for HEV systems. 


\subsection{Optimisation Techniques:}

Optimal control or dynamic optimisation usually attempts to minimize a cost function (or scaled sum of cost functions) over some sort of drive cycle, with a set of constraints. General form with constraints [1] and Figure 6.

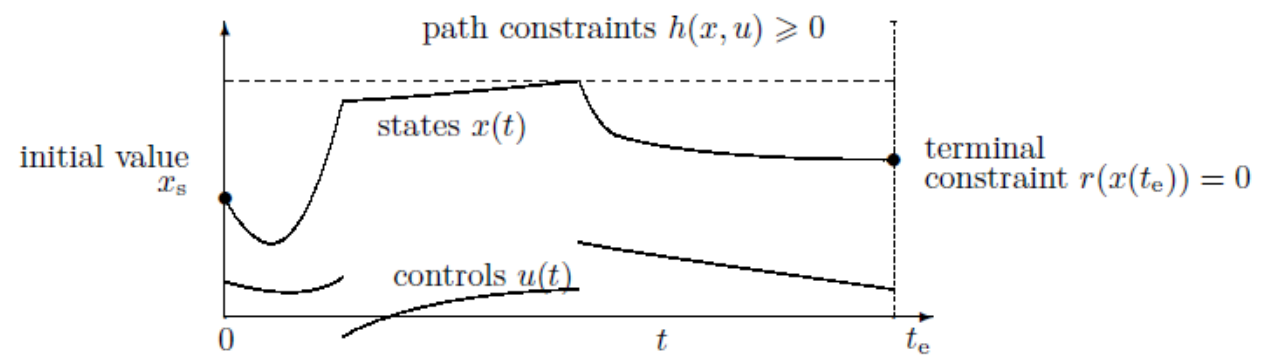

Figure 6: Simplified optimal control problem.

$$
\begin{gathered}
\min _{\substack{x, u \\
t_{f}}} J(x(t), u(t), \Lambda(t)) \\
J(x(t), u(t) m, \Lambda(t))=\int_{t_{0}} g\left(\dot{m}_{f}(t), N O_{x}, H C, C O, P N, C_{T O T}, m_{T O T}, \ldots\right) d t \\
x(0)=x_{s} \\
x(t)=f(x(t), u(t)) \\
h(x(t), u(t)) \geq 0 \\
r\left(x\left(t_{f}\right)\right)=0 \\
\Lambda(t)=\left[\begin{array}{l}
v(t) \\
s(t)
\end{array}\right]
\end{gathered}
$$

With the objective function including a scalarised function of fuelling, emissions (NOx, HC, CO, PN), total cost $\left(C_{T}\right)$ and total mass $\left(m_{T}\right)$. 
Several classifications or types exist. For example, derivative free PSO, RB, exhaustive search, SA, GA, or gradient-based such as SQP, CO. [2] includes a classification of many types of opt algs with some application areas. [3, 4] include comprehensive reviews.

Algorithms that carry out searches for the minimum with an organized trial and error routine are direct methods (ref). They may use gradients of candidate solutions to find better solutions for a problem and in doing so take the Karush-Kuhn-Tucker conditions into account, so must be differentiable. However, they do not look for an exact solution, but keep examining solutions until they converge in some way. For example, all gradients of solutions around them are positive and all double gradients are small and below some bound. Suboptimal solutions.

Algorithms using the indirect methods (ref) require convexity in the cost function and problem constraints, because without it, the sets of equations can't be solved. Depending on how you do it, it means that there is either no way to write the equations down, or the solution of the system of equations that you derive won't represent an optimum. In order to understand this, it is probably a good idea to work on a few sample problems in Boyd's book and elsewhere. By the way, the entire mathematical model of a process and the cost function for all possible points must not be convex. Convexity must only exist around the points (in time or points in state space) that represent the optimal solution. E-machines usually have mildly convex characteristics.

In general, you can try a Pontryagain formulation, but the result will probably be suboptimal. By the way, the problem will be more complicated if the control algorithm also chooses gear use or other disctrete switching actions (e.g. emachine or engine on-off). Linear programming probably isn't the way to go, because the engine maps are non-linear. The shooting method or dynamic programming may be good. Dynamic programming is probably the most reliable to benchmark a solution that is to be considered the best possible (ref?).

For the section Gasoline Hybridisation, an important factor to optimise is the PSR (Powersplit Ratio) in FH (ref?)

Whereas DP is not implementable in real-time but does find a global optimal solution, a common real-time capable optimal algorithm is PMP, special case of Euler-Lagrange equation of calculus of variations. To optimize any problem using PMP, the Hamiltonian function is formed first and then minimized with respect to control input. Then state and costate equations are obtained by following the set procedure [4].

The basic function is a Hamiltonian, in which system dynamics can be adjoined to the integrant of the cost function, using the multiplier function $\lambda(\mathrm{t})$ or co-state variable:

$$
H(x(t), u(t), \lambda(t), t)=J(x(t), u(t), \Lambda(t))+\lambda^{T}(t) \dot{x}(t)
$$

And there exists an optimum control, state and costate trajectory for which there is a minimum Hamiltonain value (with derivation in [5])

$$
H\left(x^{*}(t), u^{*}(t), \lambda^{*}(t), t\right) \leq H(x(t), u(t), \lambda(t), t) \forall x(t), u(t), t \in\left[t_{0}, t_{f}\right]
$$


The following conditions must be satisfied

$$
\begin{aligned}
\dot{\boldsymbol{x}}^{*}(\boldsymbol{t}) & =-\frac{\partial H\left(x^{*}(t), u^{*}(t), \lambda^{*}(t), t\right)}{\partial \lambda} \\
\dot{\lambda}^{*}(\boldsymbol{t}) & =-\frac{\partial H\left(x^{*}(t), u^{*}(t), \lambda^{*}(t), t\right)}{\partial x}
\end{aligned}
$$

If PMP conditions and constraints are satisfied, the solution will be extremal and if a global solution exists, it will be the global solution.

The SOC is commonly selected as the state for powertrains with electrification; [6] proves that the battery SOC monotoinically changes with the co-state $\boldsymbol{\lambda}(\mathbf{t})$. This monotonicity property can be used to iteratively find the co-state for which SOC is balanced.

In practise, a-priori knowledge of the drive cycle must be known to ensure optimality. In an extension to PMP, a real-time implementable strategy called Equivalent Consumption Minimization Strategy (ECMS), [7], by considering, for example, battery power as an equivalent fuel power, heuristic Hamiltonian functions can be formulated, using SOC setpoint

where $\mathrm{K}$ is a feedback gain parameter.

$$
\lambda(\mathrm{t})=K\left(S O C_{d e s}-S O C(t)\right)
$$

In further extensions, emissions can be added (for example NOx or other emissions), and discrete events such as gear shifts or engine pull-up/pull-down, both of which affect driveability, can be handled by discrete penalty parameters:

$$
\begin{gathered}
H(x(t), u(t), \lambda(t), t)=J(x(t), u(t), \Lambda(t))+\lambda^{T}(t) \dot{x}(t) \\
\text { where } \lambda(\boldsymbol{t})=\left[\begin{array}{c}
\lambda_{\text {SOC }} \\
\lambda_{\text {NOx }} \\
\lambda_{G S} \\
\lambda_{E P U} \\
\lambda_{E P D}
\end{array}\right], \boldsymbol{x}(\boldsymbol{t})=\left[\begin{array}{c}
\boldsymbol{S O C} \\
\boldsymbol{m}_{\text {NOx }} \\
|\boldsymbol{s i g n}(\boldsymbol{G N}(\boldsymbol{t})-\boldsymbol{G N}(\boldsymbol{t}-\boldsymbol{\delta} \boldsymbol{t}))=\mathbf{0}| \\
\boldsymbol{P}_{\text {eng }}(\boldsymbol{t})>\mathbf{0} \& \& \boldsymbol{P}_{\text {eng }}(\boldsymbol{t}-\boldsymbol{\delta} \boldsymbol{t})=\mathbf{0} \\
\boldsymbol{P}_{\text {eng }}(\boldsymbol{t})=\mathbf{0} \& \& \boldsymbol{P}_{\text {eng }}(\boldsymbol{t}-\boldsymbol{\delta} \boldsymbol{t})>\mathbf{0}
\end{array}\right]
\end{gathered}
$$

Trade-offs for on-cycle fuel, NOx, PN, etc. can create a Pareto front (Figure 7) which includes the extreme best cases (min. FC, min. NOx) and intermediate points. Advanced airpath features such as LP EGR or cylinder deactivation can be included in future assessments.

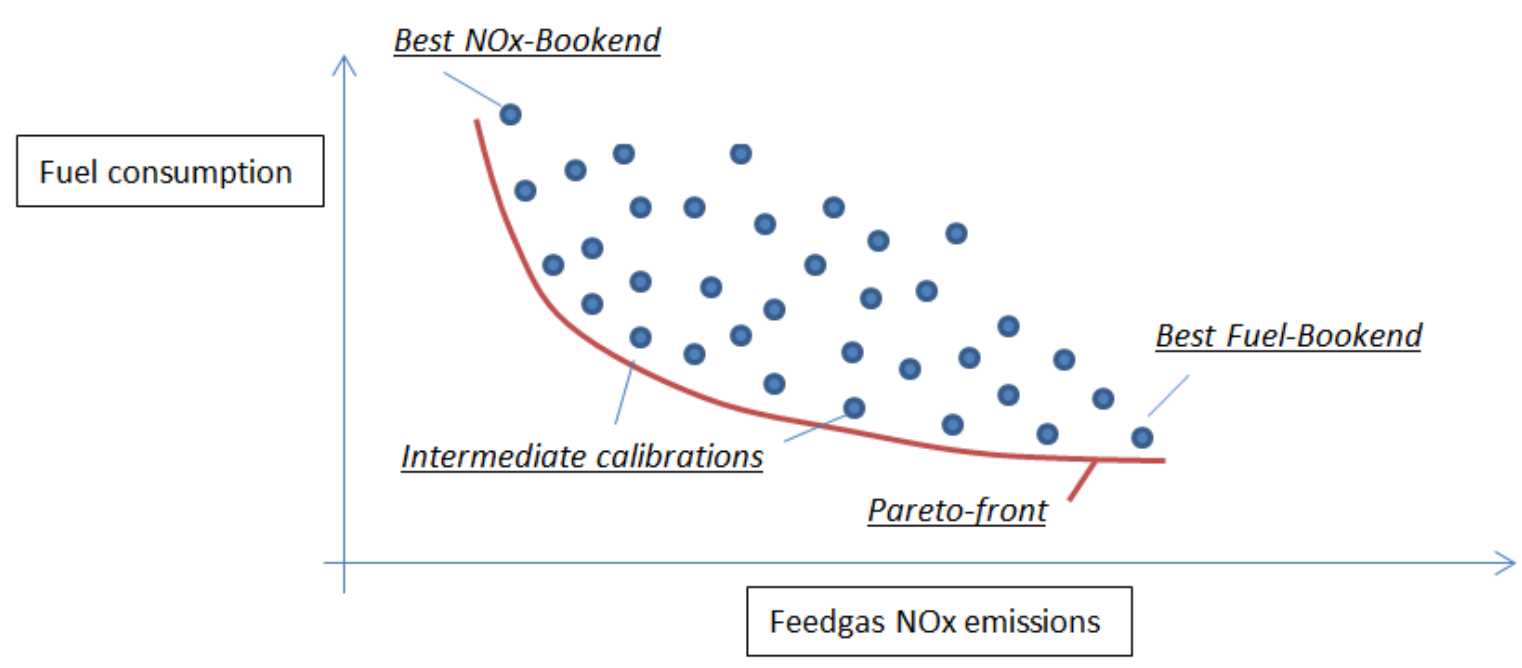

Figure 7: Fuel consumption and feedgas NOx emission tradeoff. 


\subsection{Infrastructure Extensions}

Charging, traffic/transport, communication, V2V, V2C, electrified roads ("eRoads"), many, more opportunities for optimisation, co-opt of HEV and infrastructure. For example, VII (Vehicle Infrastructure Integration) allows prediction of speed profiles to minimize energy consumption, route information or optimal ratio split for engine vs. emachine usage [].

Figure 8 illustrates a possible, generic vehicle infrastructure optimisation environment which includes the whole vehicle (and others via the Cloud).

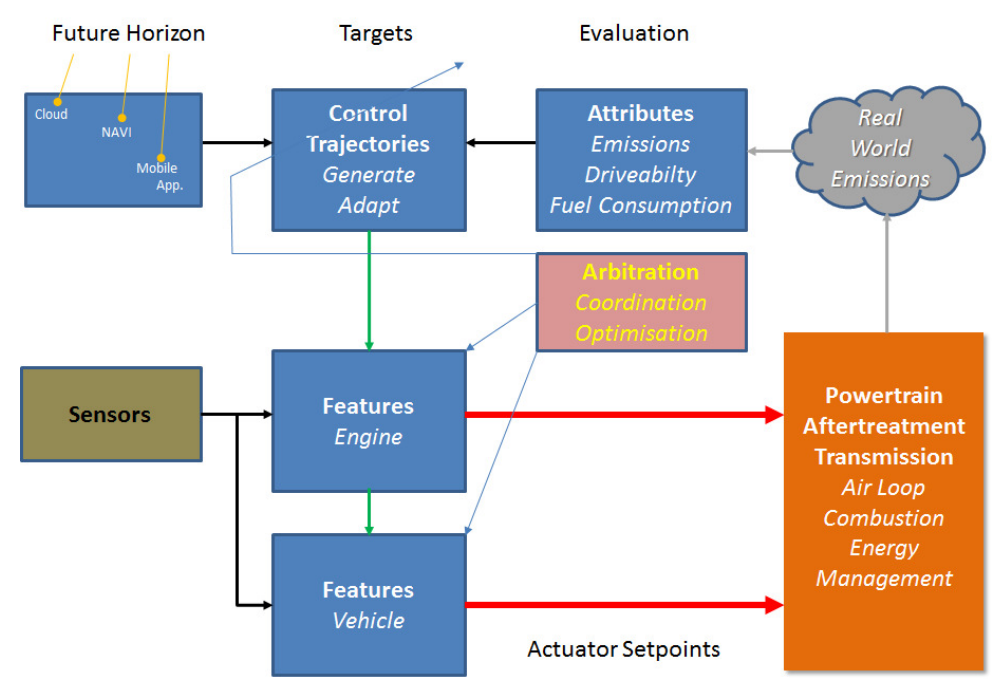

Figure 8: Infrastructure-based optimisation architecture.

\section{Drive Cycles}

2016-2017 Worldwide Emissions Standards: Passenger Cars and Light Duty, Delphi, http://delphi.com/docs/defaultsource/worldwide-emissions-standards/delphi-worldwide-emissions-standards-passenger-cars-light-duty-2016-7.pdf

Emission Test Cycles, Worldwide Harmonized Light Vehicles Test Procedure (WLTP), https://www.dieselnet.com/standards/cycles/wltp.php

1. Bart SAERENS, "Optimal Control Based Eco-Driving: Theoretical Approach and Practical Applications, " Ph.D. thesis, June 2012, Katholieke Universiteit Leuven - Faculty of Engineering

2. Silvas, E., Hofman, T., Etman, L., Steinbuch, M., "Review of Optimization Strategies for System-Level Design in Hybrid Electric Vehicles," IEEE Transactions on Vehicular Technology, March 2016, DOI: 10.1109/TVT.2016.2547897

3. D. E. Kirk. Optimal Control Theory - An Introduction. Ed. by R. W. Newcomb. Networks Series. Englewood Cliffs New Jersey: Prentice-Hall, 1970.

4. Sciarretta A, Guzzella L., "Control of hybrid electric vehicles - optimal energy management strategies," IEEE Contr Syst Mag 2007(April):60-70.

5. Aishwarya Panday and Hari Om Bansal, "A Review of Optimal Energy Management Strategies Electric Vehicle," International Journal of Vehicular Technology, Volume 2014, Article ID 160510, http://dx.doi.org/10.1155/2014/160510

6. Mohd Azrin Mohd Zulkefli a, Jianfeng Zheng b, Zongxuan Sun a, , Henry X. Liu b, 1 , "Hybrid powertrain optimization with trajectory prediction based on inter-vehicle-communication and vehicle-infrastructureintegration," Transportation Research Part C 45 (May 2014) pp. 41-63

7. Kim, Namwook; Cha, Suk Won; Peng, Huei; "Optimal Equivalent Fuel Consumption for Hybrid Electric Vehicles" , IEEE TRANSACTIONS ON CONTROL SYSTEMS TECHNOLOGY, VOL. 20, NO. 3, MAY 2012.

8. L. Guzzella, A. Sciarretta. Vehicle Propulsion Systems, ISBN 3-540-25195-2, Springer, 2005.

9. C. Desai and S. S. Williamson, "Optimal design of a Parallel hybrid electric vehicle using Multi-Objective Genetic Algorithms,” in IEEE Vehicle Power and Propulsion Conference, pp. 871-876, 2009. 
10. Theo Hofman, Søren Ebbesen, and Lino Guzzella, "Topology Optimization for Hybrid Electric Vehicles With Automated Transmissions," IEEE TRANSACTIONS ON VEHICULAR TECHNOLOGY, VOL. 61, NO. 6, JULY 2012, pp. 2442-2451.

11. Cong Hou, Minggao Ouyang $\Uparrow$, Liangfei Xu, Hewu Wang, "Approximate Pontryagin's minimum principle applied to the energy management of plug-in hybrid electric vehicles," Applied Energy · February 2014, DOI: 10.1016/j.apenergy.2013.11.002

12. JunWang, Qing-nianWang, Peng-yuWang, and Xiao-hua Zeng, "The Development and Verification of a Novel ECMS of Hybrid Electric Bus,” Mathematical Problems in Engineering Volume 2014, Article ID 981845, 14 pages http://dx.doi.org/10.1155/2014/981845

13. M. Koot, J. Kessels, B. de Jager, W. Heemels, P. van den Bosch, M. Steinbuch. Energy Management Strategies for Vehicular Power Systems. IEEE Trans. on Vehicular Tech., Vol. 54, No. 3, pp. 1-11, May 2005.

14. Y. He, M. Chowdhury, Y. Ma, and P. Pisu, "Merging mobility and energy vision with hybrid electric vehicles and vehicle infrastructure integration,” Energy Policy, vol. 41, pp. 599-609, 2012.

15. N. Murgovski, L. Johannesson, and B. Egardt, "Optimal Battery Dimensioning and Control of a CVT PHEV Powertrain," IEEE Transactions on Vehicular Technology, vol. 63(5), pp. 2151-2161, 2014.

16. T. Bradley and A. Frank, "Design, demonstrations and sustainability impact assessments for plug-in hybrid electric vehicles," Renewable and Sustainable Energy Reviews, vol. 13, pp. 115-128, 2009.F. Chen, N. Taylor, and N. Kringos, "Electrification of roads: Opportunities and challenges," Applied Energy, vol. 150, pp. 109 - 119, 2015.

17. Jungme Park, ZhiHang Chen, Ming Kuang, Member, IEEE, Abul Masrur, Senior Member, IEEE, Anthony Phillips, Member, IEEE, Yi L. Murphey, Senior Member, IEEE, "Intelligent Vehicle Power Control based on Prediction of Road Type and Traffic Congestions," Vehicular Technology Conference, 2008, VTC 2008-Fall, IEEE 68th. Publication Date 21-24 Sept. 2008.

18. P. Steinbauer 1, J. Husák, F. Pasteur, P. Denk, J. Macek, Z. Šika, „Predictive control of commercial e-vehicle using a priori route information,” 3rd Biennial International Conference on Powertrain Modelling and Control Testing, Mapping and Calibration, 7-9 Sep., 2016, Loughborough University. 


\section{References}

1. Bristol, E. H. (1966). On a new measure of interaction for multivariable process control. IEEE Trans. Automatic Control AC-11, 133-134.

2. Guo, Q. and Liu, B., "Simulation and Physical Measurement of Seamless Passenger Airbag Door Deployment," SAE Technical Paper 2012-01-0082, 2012, doi:10.4271/2012-01-0082.

3. Skogestad, S., Postlethwaite, I., "MULTIVARIABLE FEEDBACK CONTROL Analysis and design," 3.6.2, pp. 95-98.

4. Am'ezquita-Brooks, L., Ugalde-Loo, C., Lic'eaga-Castro, E., Lic'eaga-Castro, J., THE EVOLUTION OF THE RELATIVE GAIN ARRAY MATRIX: THE MULTIVARIABLE STRUCTURE FUNCTION, PHYSCON 2013, Mexico, 26-29th August, 2013

5. Jeffrey A. Cook, Jing Sun, Julia H. Buckland, Ilya V. Kolmanovsky, Huei Peng, and Jessy W. Grizzle, "AUTOMOTIVE POWERTRAIN CONTROL - A SURVEY," Asian Journal of Control, Vol. 8, No. 3, pp. 237-260, September 2006

6. B. Ashok*, S. Denis Ashok, C. Ramesh Kumar, "A review on control system architecture of a Sl engine management system," , Annual Reviews in Control (2016), http://dx.doi.org/10.1016/j.arcontrol.2016.04.005 